\title{
Acesso à informação pública e a cultura organizacional de uma universidade federal na região norte do Brasil: aceitação ou resistência?
}

\author{
Merabe Carvalho Ferreira da Gama \\ Universidade Federal Rural da Amazônia, Biblioteca, Belém, PA, Brasil \\ merabecarvalho@yahoo.com.br
}

Carlos André Corrêa de Mattos

Universidade Federal do Pará, Faculdade de Administração, Belém, PA, Brasil

carlosacmattos@hotmail.com

DOI: https://doi.org/10.26512/rici.v12.n1.2019.19135

Recebido/Recibido/Received: 2018-05-28

Aceitado/Aceptado/Accepted: 2018-11-14

Resumo: Analisa a percepção dos servidores de uma universidade federal brasileira com relação à política de amplo acesso à informação pública, amparada pela Lei n. 12.527/2011. A metodologia, de caráter exploratório e descritivo, feita na forma de pesquisa de campo, utilizou como instrumento de coleta de dados o questionário adaptado de Da Matta (2011), organizado com assertivas em escala de Likert, que versavam sobre o acesso à informação. Os dados foram tratados com estatística descritiva e inferencial. A pesquisa concluiu que os servidores compreendem o acesso à informação como um direito da sociedade, mas temem pelo uso dessas informações.

Palavras-chave: Brasil. direito à informação. transparência pública. universidades.

Access to public information and the organizational culture of a federal university in the north region of Brazil: acceptance or resistance?

Abstract: It analyzes the perception of the officers of a Brazilian federal university regarding the policy of broad access to public information, supported by Law number 12,527/2011. The methodology has an exploratory and descriptive character. The data collection tool was the questionnaire adapted from Da Matta (2011), organized with Likert scale assertions, which deal with access to information. The data were treated with inferential and descriptive statistics. The research concluded that officers understand access to information as a right of society, but fear for the use of this information.

Keywords: Brazil. public transparency. right to information. universities. 
Acceso a la información pública y la cultura organizacional de una universidad federal en la región norte del Brasil: ¿aceptación o resistencia?

Resumen: Se analiza la percepción de los servidores de una universidad federal brasileña con relación a la política de amplio acceso a la información pública, amparada por la Ley n. 12.527/2011. La metodología, de carácter exploratorio y descriptivo, hecha en la forma de investigación de campo, utilizó como instrumento de colecta de datos el cuestionario adaptado de Da Matta (2011), organizado con asertivas a escala de Likert, que versaban sobre el acceso a la información. Los datos fueron tratados con estadística descriptiva e inferencial. La investigación concluyó que los servidores comprenden el acceso a la información como un derecho de la sociedad, pero temen por el uso de esa información.

Palabras clave: Brasil. derecho a la información. transparencia pública. universidades.

\section{Introdução}

O acesso à informação é um direito humano previsto no artigo 19 da Declaração Universal dos Direitos do Homem (ORGANIZAÇÃO DAS NAÇÕES UNIDAS, 1948). Caracterizado como uma condição essencial para a transparência pública (FACHIN, 2014; UVALLE BERRONES, 2016), o acesso à informação está fortemente relacionado com aspectos contemporâneos da administração pública, como o exercício da cidadania, a presença da democracia, o controle social e o combate à corrupção (BRASIL. CONTROLADORIA GERAL DA UNIÃO, 2011; MEDEIROS; MAGALHÃES; PEREIRA, 2014; ANDRADE; CARDOSO, 2014; FROTA, 2014; BERNARDES; SANTOS, ROVER, 2015).

Apesar de ser debatido há mais de 200 anos, só recentemente o acesso à informação assumiu posição central na agenda política mundial (VIEIRA, 2013; TERRA, 2014; ZORZAL, 2015; RUIJER, 2017; BARROS, 2017). Nessa direção, diversas leis foram aprovadas, em diferentes países do mundo, como México, Japão, Peru, entre outros, revelando a preocupação de assegurar o livre acesso às informações públicas (MENDEL, 2009). No contexto brasileiro, o acesso à informação pública foi previsto desde a Constituição de 1988, mas, apesar das legislações intermediárias, esse acesso foi regulamentado de fato apenas em 2011, após a promulgação da Lei n. 12.527, conhecida como Lei de Acesso à Informação (LAI).

Nesse sentido, Da Matta (2011) investigou as organizações públicas brasileiras e constatou que, além dos desafios de infraestrutura e de processos organizacionais, a cultura dessas organizações poderia repercutir negativamente em uma política de amplo acesso à informação pública. Corroborando os desafios identificados por Da Matta (2011), o relatório da Controladoria Geral da União - CGU (2017) mostra que, mesmo considerando a Lei n. 12.527 e as legislações complementares, diversas ações ainda precisam ser implementadas 
para consolidar uma política pública de amplo acesso à informação no Brasil e, provavelmente, um dos principais indicativos dessa situação tenha sido relatado nos dados da transparência ativa, que mostram que apenas $17 \%$ dos órgãos consultados pela CGU (2016) declararam ter publicado dados e divulgado informações espontaneamente.

Nesse contexto, observa-se que ainda persiste no serviço público brasileiro o que Da Matta (2011) classificou como uma cultura do segredo, aspecto que limita uma ampla política de livre acesso à informação pública. Behlke (2014) destaca que o segredo nas organizações públicas brasileiras pode ser explicado, em grande parte, pela instabilidade política brasileira e pelos diversos eventos ocorridos na história nacional, como, por exemplo, a ditadura militar no século passado. $O$ autor afirma ainda que são perceptíveis nas organizações públicas nacionais posturas patrimonialistas, decorrentes do modo de colonização do país e do contexto cultural e social em que essas organizações foram criadas e se desenvolveram.

Desse modo, observa-se que, embora sejam grandes os desafios de infraestrutura e de processos organizacionais, uma política efetiva de livre acesso à informação pública ainda precisará enfrentar uma mudança na cultura das organizações públicas, uma vez que, como destaca Warrick (2017), a cultura organizacional se constitui com base nas crenças predominantes em uma organização e se manifesta nos valores, atitudes, comportamentos e práticas organizacionais. Nessa perspectiva, Bergue (2011) reforça ao afirmar que a cultura das organizações públicas brasileiras é uma cultura forte e resistente a mudanças.

Desta forma, a presente investigação busca sistematizar aspectos da cultura organizacional de uma universidade federal brasileira, quanto a aspectos da política de acesso à informação. $O$ estudo está organizado em seis seções, incluindo a presente introdução. A segunda seção estrutura-se no acesso à informação sob a perspectiva da transparência pública e do direito à informação. A seção seguinte, terceira seção, mostra um breve panorama sobre o acesso à informação no contexto acadêmico nacional e internacional. A quarta seção concentra-se na metodologia, classifica o estudo e descreve os procedimentos utilizados na pesquisa. A quinta seção apresenta e discute os resultados encontrados e a sexta seção estabelece as considerações finais.

\section{Acesso à informação sob a perspectiva da Transparência pública e Direito à Informação}

Acesso à informação é um tema transversal e se relaciona com vários outros aspectos presentes no contexto das organizações públicas, destacando-se, entre eles, a transparência. Tristão $(2002$, p. 1) afirma que a transparência na administração pública é a "democratização do acesso às informações, em contraposição ao sigilo". Braga (2011, p. 4) reforça essa compreensão ao definir "transparência como a atuação do órgão público no sentido de tornar 
sua conduta cotidiana, e os dados, dela decorrentes, acessíveis ao público em geral". Desse modo, o acesso à informação é condição essencial para assegurar a transparência das ações executadas pelos órgãos públicos.

Embora as principais discussões sobre o acesso à informação sejam recentes, a busca para obter acesso a informações públicas remonta a tempos antigos. No século XVIII, o acesso a informações públicas ganhou status de princípio com a Revolução Francesa, porém, no século seguinte, seu avanço foi limitado, ganhando ênfase apenas a partir do século XX, após a segunda guerra mundial, quando organismos internacionais e sociedade civil passaram a the atribuir maior importância (BATISTA, 2012; FERREIRA; SANTOS; MACHADO, 2012; MARTINS; REIS, 2014; LIMA; CORDEIRO; GOMES, 2014). Anos depois, o fim da Guerra Fria, aliado ao processo de democratização de países do terceiro mundo e aos colapsos ocorridos nas economias centralizadas, pressionou para que fossem instituídas legislações que garantissem o acesso à informação pública (LIMA; CORDEIRO; GOMES, 2014).

Informação pública é sinônima de informação governamental e se refere à informação produzida, editada, publicada ou disseminada pelos entes do governo ou mantidas sob sua guarda. É importante destacar que o conceito abrange todos os setores e níveis do governo (UHLIR, 2006; CUNHA; CAVALCANTI, 2008; BATISTA, 2010). Além disso, Moura (2014) esclarece que a informação pública pode ser produzida por um ente do governo ou em cooperação com outras organizações, ou até mesmo ter sido adquirida de outras pessoas. Para Batista (2010, p. 40), a informação pública tem status de bem público. Conforme a autora, esse bem tem caráter:

[...] tangível ou intangível, com forma de expressão gráfica, sonora e/ou iconográfica, que consiste num patrimônio cultural de uso comum da sociedade e de propriedade das entidades/instituições públicas da administração centralizada, das autarquias e das fundações públicas. A informação pública [...] [deve estar] [...] disponível ao interesse público/coletivo da sociedade. Quando acessível à sociedade, a informação pública tem o poder de afetar elementos do ambiente, reconfigurando a estrutura social.

O acesso à informação é um tema inserido numa discussão mais profunda da governança da administração pública, pois o direito à informação é entendido como um direito precursor, capaz de originar outros diretos, o que the confere status de condição para o exercício de um conjunto de direitos de ordem política e social (LIMA; CORDEIRO; GOMES, 2014). O direito à informação inclui o dever de informar, portanto, de veicular a informação, 
além do direito de receber informações e do direito de se informar, sendo este direito exercido por meio de pesquisa e coleta de informações. Esse conjunto de direitos compõe o que se compreende como base democrática de um país (LIMA; CORDEIRO; GOMES, 2014). Nesse sentido, Batista (2014) entende que o direito à informação trata essencialmente da permissão, expressa em lei, para que os cidadãos tenham acesso à informação pública.

Indolfo (2013) complementa e destaca que, quando o cidadão obtém informações, ele adquire também melhores condições para exigir outros direitos essenciais e básicos, como educação e saúde. Segundo a autora, o acesso à informação pública é fundamental para a ampliação e a consolidação de direitos políticos, econômicos e sociais. Essa compreensão justifica tanto a necessidade, quanto a legitimidade do direto de acesso às informações públicas custodiadas pelas organizações públicas.

\section{Acesso à informação: um breve panorama nas investigações e aspectos relacionados com} transparência e a cultura organizacional

O acesso à informação e a transparência pública são temas de destaque e constituem uma preocupação central para diversos organismos nacionais e internacionais (ARTIGO, 19, 2009; BRASIL. CONTROLADORIA GERAL DA UNIÃO, 2013; ORGANIZAÇÃO DAS NAÇÕES UNIDAS, 2017). No âmbito acadêmico, observa-se que as pesquisas vêm se dedicando à temática, tendo assumido, com o passar do tempo, projeção mundial.

No âmbito internacional, Giménez Chornet et al. (2013) estudaram a transparência pública de municípios na região de Valência, na Espanha, e constataram que o índice de transparência é baixo. Por outro lado, Barrero Rodríguez (2014), em uma análise sobre a Lei de Transparência na Andaluzia, também na Espanha, constatou que a Lei representava um avanço que materializava o fortalecimento da democracia. Contudo, como Da Matta (2011), no Brasil, Barrero Rodriguez (2014) também ressaltou a necessidade de mudança na cultura dos órgãos da Administração Pública da Andaluzia.

Outro estudo com foco na transparência pública ocorreu no México, conduzido por Fox, Haight e Palmer-Rubin (2011). Nele, os autores identificaram que, apesar de o país ter passado por várias reformas para tornar o governo mais transparente, o México ainda enfrentava desafios, inclusive culturais, que promoviam grande resistência ao acesso à informação pública. Posteriormente, Sandoval Ballesteros (2013) reforçou essa compreensão, ao afirmar que a trajetória da transparência pública mexicana era paradoxal, uma vez que o país promoveu mecanismos legais de acesso à informação e transparência, porém observa um intenso processo de burocratização que dificulta o acesso às informações públicas. 
Ramos Volonterio e Villar (2013) dissertaram sobre o acesso à informação no Uruguai. Assim como outros autores internacionais, as autoras também reforçam o entendimento de que o acesso à informação é fundamentado na transparência e mencionam que se não for assim, a Lei de Acesso à informação daquele país corre o risco de se tornar "letra morta".

Ruijer (2017) destaca que as últimas décadas proporcionaram uma maior compreensão em termos de transparência pública, mas ainda há muito a avançar. $\mathrm{O}$ autor realizou um estudo comparativo sobre a proatividade de agentes públicos com relação à transparência em dois países democráticos, que têm uma longa tradição de transparência: Estados Unidos e Holanda. Os resultados da pesquisa mostraram que os servidores americanos estão mais envolvidos na divulgação proativa de informações do que os holandeses, mas que, em alguns casos, a transparência ainda é distorcida. Esses trabalhos mostram que, embora o direito de acesso à informação exista desde o século XIX, ele ainda não está consolidado, revelando um problema de Administração Pública de repercussão mundial.

Assim como em outros países, no Brasil, a transparência pública e o acesso à informação também vêm sendo debatidos. No âmbito acadêmico, além de ser tema de diversos artigos, também figura como objeto de estudo de teses de doutorado sob diferentes perspectivas encontradas em Gama (2015), Zorzal (2015), Cruz (2016), Lyrio (2016), Barros (2017), entre outros. As pesquisas também têm se concentrado no âmbito do acesso à informação sob a perspectiva das universidades públicas (TERRA, 2014; CARVALHO, 2014; MIRANDA, 2015; GAMA, 2015; SOUZA et al., 2015; ZORZAL, 2015; BARROS, 2017), procurando compreender os diferentes aspectos que o tema envolve e propondo melhorias que auxiliem no fortalecimento dessas instituições.

Na perspectiva das universidades públicas brasileiras, observa-se que o acesso à informação pode revelar-se de forma contraditória, isto porque, embora estas instituições tenham no cerne de sua missão, o compartilhamento, a transferência e a disseminação de informações, que ocorrem tanto no processo de ensino, quanto na divulgação de pesquisas científicas, dados da Controladoria Geral da União $(2014 ; 2016)$ mostram que as universidades federais representam a categoria de órgãos públicos que menos contribuem para o acesso à informação no Brasil. Quando comparadas com outros órgãos do poder executivo federal, as universidades são as principais responsáveis por omissões a pedidos de informação, apresentam o menor índice de resposta e lideram o índice de reclamação de cidadãos quanto ao atendimento da LAI.

Importante ressaltar que apesar de ações da CGU, o atendimento das universidades à LAI tem piorado. Como exemplo, em 2014, as universidades respondiam por quase metade das omissões a pedidos de informação no governo federal (49\%). Já em 2015, essas instituições 
foram responsáveis por $70 \%$ de todas as omissões ocorridas. Assim, é importante compreender esses aspectos sob a perspectiva dos próprios servidores públicos, uma vez que esses agentes são responsáveis pela disponibilização das informações públicas.

Ao considerar os efeitos operacionais de uma política de amplo acesso às informações públicas, destaca-se a necessidade de essas organizações normatizarem procedimentos e investirem em infraestrutura para, por um lado, assumirem uma postura ativa na prestação das informações e, por outro lado, atenderem as demandas oriundas de outras organizações e da sociedade em geral. Esse processo implica naturalmente mudanças, que são fortemente impactadas por aspectos relacionados com a cultura organizacional, uma vez que é a cultura da organização que exprime a forma tida como correta de fazer as coisas, sendo seus pressupostos profundamente arraigados na organização (McSHANE; GLINOW, 2013).

Warrich (2017) destaca que, apesar de existirem diversos conceitos para a cultura organizacional e apesar de a cultura já ser estudada há muito tempo pela antropologia, as constatações mais recentes mostram que a cultura conserva relação de proximidade com o desempenho da organização e quanto mais forte a cultura, maior será sua influência no comportamento dos integrantes da organização. Assim, como destaca o autor, compreender claramente aspectos da cultura é essencial para promover o comportamento desejado. Complementarmente, Barale e Santos (2017) reforçam a necessidade de compreender a cultura organizacional antes de qualquer proposta de intervenção organizacional.

\section{Método}

Classificado como quantitativo, com alcance exploratório e descritivo e desenho não experimental do tipo transversal, a presente pesquisa utilizou dados primários obtidos em pesquisa de campo. A pesquisa, de recorte institucional, foi iniciada pelo levantamento do número de servidores em atuação no campus Belém, da Universidade Federal Rural da Amazônia - UFRA, local da pesquisa de campo. Na ocasião, foram identificados 583 servidores, que formaram o universo da pesquisa. O processo de amostragem foi probabilístico aleatório simples, e o tamanho da amostra foi calculado com $90 \%$ de margem de segurança e $6 \%$ de margem de erro, o que resultou em 183 entrevistados. O cálculo da amostra foi feito conforme a Fórmula 1, apresentada em Gil (2014, p. 97).

Fórmula 1: Cálculo da amostra

$$
n=\frac{\sigma^{2} p \cdot q \cdot \mathbb{N}}{e^{2}(\mathbb{N}-1)+\sigma^{2} p \cdot q}
$$

Fonte: Gil (2014, p. 97) 
Em que $n=$ tamanho da amostra; $\sigma^{2}=$ nível de confiança (em número de desvios padrão); $p$ = percentagem com a qual o fenômeno se verifica; $q$ = percentagem complementar; $\mathrm{N}=$ tamanho da população; e $\mathrm{e}^{2}=$ erro amostral ao quadrado.

O instrumento de coleta de dados foi o questionário estruturado, desenvolvido com base em Da Matta (2011). Organizado em duas seções, a primeira seção do questionário permitiu identificar o perfil do entrevistado, especialmente quanto ao gênero, escolaridade, forma de admissão no serviço público, tempo de serviço, entre outros. Nesta seção, as respostas foram elaboradas na forma fechada, com alternativas dicotômicas e de múltipla escolha. A segunda parte do questionário foi formada por 20 afirmativas que pesquisaram aspectos relacionados com uma política de amplo acesso à informação pública. Na segunda seção do questionário, as respostas foram em escala de Likert, com sete opções de respostas, estendendo-se desde 1 para "Discordo Totalmente", 2 "Discordo Muito", 3 "Discordo", 4 "Não Discordo Nem Concordo" ou "Não sei", 5 "Concordo", 6 "Concordo Muito" e 7 "Concordo Totalmente".

O instrumento de coleta de dados foi submetido ao pré-teste, conforme as recomendações de Malhotra (2012), Samara e Barros (2007) e Hair et al. (2009). Responderam ao pré-teste, 24 servidores. Na ocasião, foi observado o tempo para resposta e possíveis dúvidas dos entrevistados. Após esse procedimento, o questionário foi ajustado quanto a alguns aspectos de semântica para facilitar a compreensão dos entrevistados e então, aplicado definitivamente. Ao final da pesquisa de campo, foram obtidos 185 questionários, sendo 7 descartados por erros no preenchimento, ou por apresentarem muitos dados ausentes (missing values). Esse aspecto elevou levemente a margem de erro da amostra dos 6\% previstos para $6,12 \%$ obtidos ao final do processamento dos questionários. Os dados foram tratados com estatística descritiva e inferencial. Quanto ao tratamento descritivo, foram utilizadas a distribuição de frequência, média e desvio padrão. Já com relação a estatística inferencial foi empregado o teste T para uma amostra (One sample T-test), representado pela Fórmula 2 (BRUNI, 2012, p. 173).

Fórmula 2: Teste $t$ para uma amostra

$$
t=\frac{\bar{x}-\mu_{0}}{\frac{s}{\sqrt{n}}}
$$

Fonte: Bruni $(2012,173)$ 
Em que: $\bar{x}$ é a média da amostra; $\mu$ a média da população; s é o desvio padrão; e $n$ é o número de observações.

$\mathrm{Na}$ interpretação dos resultados as respostas foram sumarizadas conforme os seguintes critérios: (1) as respostas na escala de Likert entre 1 e 3 foram somadas e consideradas discordantes; (2) as respostas marcadas como 4, foram consideradas neutras; e (3) as respostas de 5 a 7 foram somadas e consideradas concordantes. Após esses procedimentos e a representação dos resultados na forma de tabela, foram calculados os escores médios, que serviram de base para a aplicação do teste T. A opção pelo teste paramétrico foi auferir se os escores das repostas eram significativamente diferentes do centro da escala $(4,00)$ e, com isso, afirmar que, de maneira geral, a cultura organizacional seria receptiva, ou não, a política de amplo acesso a informação pública. Para tanto, foram formuladas as seguintes hipóteses:

$H_{0}: \mu \leq 4,00$, ou seja, não existem evidências estatísticas para afirmar que a cultura organizacional seja receptiva ao amplo acesso a informação pública.

$H_{1}: \mu>4,00$, ou seja, existem evidências estatísticas para afirmar que a cultura organizacional é receptiva ao amplo acesso a informação pública.

Nessas condições, o teste $T$ foi selecionado para verificar se a média populacional se comportaria conforme $\mathrm{H}_{0}$. Assim, o teste assumiu caráter unilateral à direita e teve como regra de decisão para rejeitar $\mathrm{H}_{0}$ se a sig. $\leq \frac{\alpha}{2}$ e o sinal da estatística de teste fosse positivo ( $\left.\mathrm{t}>0\right)$. 0 nível de significância escolhido para rejeitar ou aceitar $\mathrm{H}_{0}$ foi de $5 \%(\alpha=0,05)$ e a verificação da normalidade da distribuição amostral, exigência para utilização do teste $T$, foi atendida, pois, o tamanho da amostra ( $n=175)$ foi superior ao Teorema do Limite Central (TLC) e o coeficiente de assimetria $(0,305)$ mostrou que a distribuição não era fortemente assimétrica. Esses aspectos possibilitaram verificar a adequação do teste.

\section{Resultados e discussão}

O perfil dos entrevistados reuniu os aspectos típicos da amostra. A pesquisa iniciou pela presença de função comissionada ou cargo de direção, na sequência, pelo tempo de serviço no cargo, faixa etária, gênero, escolaridade e a forma de admissão no serviço público (Tabela 1).

Tabela 1 - Perfil dos entrevistados

\begin{tabular}{llll}
\hline Características & Categorias & Frequência & Percentual \\
\hline \multirow{2}{*}{ Exercício de cargo comissionado } & Exerce cargo comissionado & 52 & 29,20 \\
& Não exerce cargo comissionado & 126 & 70,80 \\
\hline Tempo de serviço no cargo (em & Menos de 1 ano & 7 & 3,90
\end{tabular}




\begin{tabular}{|c|c|c|c|}
\hline \multirow[t]{4}{*}{ anos) } & 1 a 5 & 62 & 34,80 \\
\hline & 6 a 10 & 18 & 10,10 \\
\hline & 11 a 20 & 26 & 14,60 \\
\hline & Acima de 20 & 65 & 36,60 \\
\hline \multirow{6}{*}{ Faixa etária } & 18 a 25 & 4 & 2,20 \\
\hline & 26 a 33 & 35 & 19,70 \\
\hline & 34 a 41 & 24 & 13,50 \\
\hline & 42 a 49 & 22 & 12,40 \\
\hline & 50 a 57 & 54 & 30,30 \\
\hline & Acima de 58 & 39 & 21,90 \\
\hline \multirow{2}{*}{ Gênero } & Masculino & 99 & 55,61 \\
\hline & Feminino & 79 & 44,39 \\
\hline \multirow{6}{*}{ Escolaridade } & Fundamental & 6 & 3,4 \\
\hline & Médio & 40 & 22,5 \\
\hline & Superior & 40 & 22,5 \\
\hline & Especialização & 46 & 25,8 \\
\hline & Mestrado & 19 & 10,7 \\
\hline & Doutorado & 27 & 15,1 \\
\hline \multirow{3}{*}{$\begin{array}{l}\text { Forma de admissão no serviço } \\
\text { público }\end{array}$} & Concurso público & 145 & 81,50 \\
\hline & Contrato temporário & 7 & 3,90 \\
\hline & Contratação sem concurso & 26 & 14,60 \\
\hline
\end{tabular}

Fonte: Pesquisa de campo, 2017

Observa-se que os entrevistados, na maioria, não exerciam funções gratificadas, nem cargos de direção (70,80\%). Quanto ao gênero, a amostra foi predominantemente masculina $(55,61 \%)$, com idade acima de 50 anos $(52,20 \%)$ e escolaridade superior ou pós-graduação $(74,10 \%)$. Quanto às características profissionais, a maior parte dos entrevistados ingressou no serviço público por concurso $(81,50 \%)$ e, no geral, tinham mais de onze anos de tempo de serviço $(51,20 \%)$ por ocasião das entrevistas.

\subsection{Percepção dos entrevistados quanto ao acesso à informação}

A Tabela 2 mostra os resultados das 20 assertivas quanto à avaliação da política de acesso à informação. Entre esses resultados, destacam-se aspectos como transparência, aumento na satisfação do trabalho, mau uso das informações, maior burocratização da administração pública, entre outros. Os resultados do tratamento dos dados permitiram observar que os entrevistados reconhecem que a implantação de uma política de acesso à informação representa um avanço para a administração pública (87,80\%).

Os servidores concordam que uma política dessa natureza traz impactos positivos, como mais transparência nas atividades da Administração Pública $(86,40$ \%), promoção do fortalecimento, da credibilidade e melhoria da imagem da Administração Pública perante a sociedade (86,00 \%), aumento da confiança do cidadão na Administração Pública $(80,90 \%)$ e ampliação substancial do acesso à informação da Administração Pública disponibilizada para a 
sociedade $(81,50 \%)$, condição que contribui para maior aproximação entre o cidadão e a Administração Pública (82,10\%).

Tabela 2 - Impactos da implantação da política de acesso à informação na perspectiva dos entrevistados

\begin{tabular}{|c|c|c|c|c|c|}
\hline \multirow{2}{*}{ Características } & \multicolumn{3}{|c|}{ Percentuais (em \%) } & \multirow{2}{*}{ Média } & \multirow{2}{*}{$\begin{array}{l}\text { Desvio } \\
\text { Padrão }\end{array}$} \\
\hline & 1 a 3 & 4 & 5 a 7 & & \\
\hline $\begin{array}{l}\text { Mais transparência sobre as atividades da Administração } \\
\text { Pública }\end{array}$ & 7,40 & 6,20 & 86,40 & 5,61 & 1,34 \\
\hline $\begin{array}{l}\text { Fortalecimento da credibilidade e melhoria da imagem da } \\
\text { Administração Pública }\end{array}$ & 8,40 & 5,60 & 86,00 & 5,54 & 1,26 \\
\hline $\begin{array}{l}\text { Aumento da confiança do cidadão na Administração } \\
\text { Pública. }\end{array}$ & 9,60 & 9,60 & 80,80 & 5,39 & 1,41 \\
\hline Maior respeito aos direitos humanos & 12,9 & 8,50 & 78,60 & 5,34 & 1,38 \\
\hline $\begin{array}{l}\text { Ampliação substancial do acesso à informação da } \\
\text { Administração Pública }\end{array}$ & 8,40 & 10,10 & 81,50 & 5,33 & 1,35 \\
\hline Redução, combate e prevenção da corrupção & 14,60 & 8,40 & 77,00 & 5,33 & 1,50 \\
\hline Aproximação entre o cidadão e a Administração Pública & 9,50 & 8,40 & 82,10 & 5,26 & 1,37 \\
\hline Conscientização do servidor público quanto ao seu papel & 10,70 & 9,60 & 79,70 & 5,23 & 1,32 \\
\hline $\begin{array}{l}\text { A implementação de uma política de amplo acesso do } \\
\text { cidadão à informação pública é um avanço }\end{array}$ & 6,10 & 6,10 & 87,80 & 5,23 & 1,42 \\
\hline Aumento da sua satisfação no trabalho & 21,90 & 12,40 & 65,70 & 4,80 & 1,43 \\
\hline formações obtidas & 30,90 & 26,40 & 42,70 & 4,14 & 1,59 \\
\hline Má utilização das informações obtidas & 41,10 & 23,00 & 35,90 & 3,89 & 1,63 \\
\hline Solicitações excessivas e descabidas & 44,40 & 20,80 & 34,80 & 3,82 & 1,68 \\
\hline Uso indevido dessas informações pela imprensa & 43,30 & 27,00 & 29,70 & 3,78 & 1,48 \\
\hline $\begin{array}{l}\text { Vantagens desproporcionais e indevidas para grupos de } \\
\text { interesses bem situados para obter essas informações e } \\
\text { usá-las para seus fins privados }\end{array}$ & 48,20 & 20,80 & 31,00 & 3,66 & 1,54 \\
\hline $\begin{array}{l}\text { Maior burocratização ("emperramento da máquina") da } \\
\text { Administração Pública }\end{array}$ & 54,50 & 16,30 & 29,20 & 3,62 & 1,60 \\
\hline Mais conflitos entre cidadãos e a Administração Pública & 56,70 & 15,20 & 28,10 & 3,51 & 1,57 \\
\hline Aumento da carga de trabalho do servidor público & 59,50 & 15,20 & 25,30 & 3,37 & 1,57 \\
\hline $\begin{array}{l}\text { Perda do controle de informações privativas da } \\
\text { administração pública }\end{array}$ & 57,90 & 20,20 & 21,90 & 3,35 & 1,45 \\
\hline Alienação e desmotivação do servidor público & 67,50 & 14,00 & 18,50 & 3,13 & 1,43 \\
\hline
\end{tabular}

Fonte: Pesquisa de campo, 2017.

Esses resultados permitem compreender que, de maneira geral, os servidores percebem como benéfico o acesso à informação pública na relação entre Estado e Sociedade. Destaca-se que esse conjunto de assertivas mostra certa uniformidade ao considerar que em todas elas os resultados se apresentaram acima de $80 \%$ de concordância. No mesmo sentido, percebe-se que a maioria dos entrevistados $(56,70 \%)$ discorda que a política de acesso às informações públicas possa gerar mais conflitos entre cidadãos e o Estado.

Por outro lado, ao avaliarem os impactos do acesso à informação no cotidiano de trabalho, avaliando aspectos como a maior conscientização quanto ao seu papel na organização e na sociedade, o possível aumento na satisfação no trabalho, ou mesmo a maior 
carga de trabalho ou possíveis alienação e desmotivação do servidor público, os entrevistados foram menos uniformes, mostrando maior dispersão nas respostas.

Assim, eles compreendem que uma política de amplo acesso às informações pode favorecer uma conscientização dos servidores públicos, pois 79,70\% (142) dos entrevistados manifestaram acreditar que essa política contribuirá para melhorar sua atuação na organização e na sociedade. Ao responderem se a política pode contribuir para o aumento da satisfação com o trabalho, o número de concordantes foi menor, mas alcançou a maioria dos entrevistados, com $65,70 \%$ (116) dos participantes se posicionando favoravelmente.

Em relação ao aumento da carga de trabalho, 59,50 \% (106) discordam que essa possibilidade possa ocorrer. Esse resultado foi coerente com os resultados da possibilidade de "maior burocratização" (emperramento da máquina) da administração pública", em que $54,50 \%$ (97) dos entrevistados também discordaram de sua ocorrência, uma vez que o aumento de trabalho poderia implicar impossibilidade de atendimento, considerando a quantidade de servidores alocados nas unidades administrativas atualmente.

Ao se referir às mudanças nas organizações públicas, Carapeto e Fonseca (2014) destacam que uma das causas de resistência a mudanças é o medo do aumento de trabalho. Contudo, esse aspecto não foi uma preocupação dos entrevistados, uma vez que 59,50\% (106) dos servidores entrevistados discordaram dessa possibilidade.

Ao responderem à assertiva quanto à alienação e desmotivação do servidor público, 67,40\% (119) discordaram que a política de acesso à informação possa influenciar nesse aspecto. Entretanto, cabe destacar que a pesquisa da CGU (2011, p. 16) identificou que os servidores públicos federais tendem a se preocupar com "o impacto que o atendimento a um volume expressivo de informações possa trazer para sua unidade: tempo, energia e pessoal, visto que esses recursos já são escassos". Mas isso não foi constatado pelos resultados dessa pesquisa.

Destaca-se também que o acesso à informação é um construto amplo que impacta na conquista de outros direitos (LIMA; CORDEIRO; GOMES, 2014), bem como na sustentação de um estado democrático (OLIVEIRA; RAMINELLI, 2014; INDOLFO, 2013). Desse modo, nota-se que $78,60 \%$ (140) dos entrevistados relacionam a política de amplo acesso à informação com o maior respeito aos direitos humanos. Esse aspecto é fundamental, visto que o acesso à informação se situa no âmbito dos direitos humanos, estabelecido no artigo 19 da Declaração Universal dos Direitos do Homem (ORGANIZAÇÃO DAS NAÇÕES UNIDAS, 1948).

Conforme apresentado na Tabela 2, observa-se também que 77\% (137) dos entrevistados acreditam que o acesso à informação contribua de forma efetiva para a redução na corrupção e favoreça seu combate e prevenção. Vale ressaltar que, em comparação com os 
resultados da pesquisa realizada pela CGU (2011), esse aspecto se posicionou como o segundo maior impacto da Lei 12.527/2011. Já nessa pesquisa, ocupou a quinta colocação.

Diversos estudos defendem o acesso à informação como um meio privilegiado de combate à corrupção (ANGÉLICO; TEIXEIRA, 2012; MEDEIROS; MAGALHÃES; PEREIRA, 2014; ANDRADE; CARDOSO, 2014; FROTA, 2014). O acesso à informação mostra-se efetivo nesse sentido, pois possibilita à sociedade maior capacidade de fiscalização dos recursos públicos, a partir da maior facilidade na obtenção das informações.

Quanto aos aspectos relacionados com as solicitações e uso das informações, as respostas concentraram-se na faixa inferior da escala, indicando discordância da assertiva. Nesse sentido, comparando as respostas com as demais, percebe-se que os entrevistados foram menos contundentes, destacando-se as respostas no ponto intermediário da escala. Apesar de esse comportamento não afetar na dispersão das respostas, que mantiveram os mesmos desvios padrão das demais respostas da pesquisa, a opção pelo ponto intermediário da escala sugere dúvida, ou indiferença por parte do entrevistado.

Assim, 42,70\% (76) dos servidores acreditam que o acesso à informação pode gerar um uso político desta informação, enquanto 30,90\% (55) discordam que isso possa ocorrer. Por outro lado, 41,10\% (73) discordam que as informações serão utilizadas indevidamente. Já com relação às solicitações excessivas e descabidas, $44,40 \%$ (78) dos participantes da pesquisa discordam que isso venha ocorrer.

Quanto ao "uso indevido dessas informações pela imprensa", 43,30 \% (76) dos entrevistados também discordaram dessa possibilidade. Ao analisar as "vantagens desproporcionais e indevidas para grupos de interesses bem situados para obter essas informações e usá-las para seus fins privados", o percentual de discordância aproximou-se da metade dos entrevistados, posicionando-se em 48,20\% (85). A maior discordância entre as assertivas foi a que investigou a possibilidade de "perda do controle de informações privativas da administração pública", pois 57,90\% (103) da amostra se posicionou de forma discordante, revelando, assim, reduzida possibilidade de ocorrência deste fato na opinião dos entrevistados.

Observa-se, dessa forma, que os servidores reconhecem o direito do cidadão no acesso à informação, porém quando são analisados os aspectos que envolvem o uso dessas informações, as opiniões se revelam mais dispersas. Ressalta-se que nas variáveis que analisaram os impactos relacionados às solicitações e uso das informações, optou-se por destacar a discordância do entrevistado, uma vez que em todas o percentual de discordância esteve acima de concordância. 
Cabe destacar que a maioria dessas variáveis também foram identificadas na pesquisa da CGU (2011) como os principais aspectos considerados pelos servidores, como negativos da política de amplo acesso à informação. Essas questões sugerem a elaboração de estratégias de combate para o atendimento dos preceitos estabelecidos pela Lei de Acesso à Informação. Contudo, a perspectiva de resistência a mudanças na instituição é baixa, quando se considera o acesso à informação, condição que favorece a transparência na instituição. Aspecto diferente das constatações de Bairral, Silva e Alves (2015), que identificaram baixa transparência entre instituições federais brasileiras.

\subsection{Avaliação geral quanto ao acesso à informação}

A avaliação geral foi feita pelo escore médio das respostas que foi calculado em 4,47, portanto, próximo ao centro da escala $(4,00)$. O desvio padrão dos escores foi baixo $(0,61)$, indicando que eles se posicionaram concentrados no entorno da média com baixa dispersão. Esse aspecto qualifica a média para representar as opiniões dos entrevistados. Desta forma, conforme a Tabela 2, observa-se que o escore médio foi significativamente superior a 4,00 (t $(183)=10,234 ; p<0,01)$ sendo estimado com $95 \%$ de confiança de estar entre 3,62 e 4,56 . Esse resultado, possibilita rejeitar $\mathrm{H}_{0}$ e admitir que, existem evidências estatísticas para afirmar que a cultura organizacional é receptiva à política de amplo acesso a informação pública.

Tabela 2 - Teste T para avaliação da aceitação do amplo acesso a informação pública.

\begin{tabular}{lllllll}
\hline & $\begin{array}{l}\text { Distribuição } \\
\mathrm{t}\end{array}$ & $\begin{array}{l}\text { Valor da } \\
\text { Significância }\end{array}$ & $\begin{array}{l}\text { Desvio } \\
\text { padrão }\end{array}$ & $\begin{array}{l}\text { Limites do } \\
\text { confiança }\end{array}$ & intervalo de \\
\hline Médias & 10,234 & 0,000 & 0,609 & 0,377 & 0,557 \\
\hline $\begin{array}{l}183 \text { graus de liberdade } \\
\text { confiança=95\% }\end{array}$ & & Valor de referência $=4,00$ & Intervalo de \\
\hline
\end{tabular}

Fonte: pesquisa de campo, 2017

\section{Considerações Finais}

Embora para operacionalizar a LAI sejam necessárias mudanças de caráter técnico, é preciso observar também a cultura do serviço público brasileiro. Esse estudo permitiu observar que a maior parte dos servidores na universidade estudada está aberta ao acesso à informação e a compreendem como um direito dos cidadãos. Nota-se, porém, certa preocupação dos servidores quanto ao uso da informação. Em geral, não se pode afirmar que haja resistência ao acesso às informações na universidade estudada, apenas que alguns servidores parecem olhar essa política com maior cautela. 


\section{Referências}

ANDRADE, C. C.; CARDOSO, A. M. P. O acesso à informação pública no Brasil: a Lei 12.527/2011 e as práticas sociais. In: MOURA, Maria Aparecida (Org.). A construção social do acesso público à informação no Brasil: contexto, historicidade e repercussões. Belo Horizonte: UFMG, 2014. p.107-125.

ARTIGO 19. Acesso à informação e controle social de políticas públicas. Brasília: ANDI; Artigo 19, 2009.

ANGÉLICO, F.; TEIXEIRA, M. A. C. Acesso à informação e ação comunicativa: novo trunfo para a gestão social. Desenvolvimento em questão, ljuí, v. 10, n. 21, p. 7-27, set./ dez. 2012.

BAIRRAL, M. A. C.; SILVA, A. H. C.; ALVES, F. J. dos S. Transparência no setor público: uma análise dos relatórios de gestão anuais de entidades públicas federais no ano de 2010. Revista de Administração Pública, Rio de Janeiro, v. 46, n. 3, p. 643-675, maio/jun. 2015.

BARALE, R. F.; SANTOS, B. R. Cultura organizacional: revisão sistemática da literatura. Revista Psicologia: Organizações e Trabalho, Brasília, n. 17, v. 2, p. 129-136, abr./jun. 2017.

BARBETTA, P. A. Estatística aplicada às Ciências Sociais. 9. ed. Florianópolis: Ed. da UFSC, 2014.

BARRERO RODRÍGUEZ, C. La Ley de Transparencia Pública de Andalucía: sus aportaciones al régimen establecido en el ordenamiento del Estado. Revista Andaluza de Administración Pública, Sevilla, n. 89, p. 41-74, mayo-agosto 2014.

BARROS, S. R. M. A Transparência passiva na Universidade Federal da Paraíba. 2017. 87 f. Dissertação (Mestrado em Políticas Públicas, Gestão e Avaliação do Ensino Superior) Universidade Federal da Paraíba, João Pessoa, 2017.

BATISTA, C. L. Informação pública: entre o acesso e a apropriação social. 2010. 202 f. Dissertação (Mestrado em Ciência da Informação) - Escola de Comunicações e Artes, Universidade de São Paulo, São Paulo, 2010.

BATISTA, C. L. Informação pública: controle, segredo e direito de acesso. Intexto, Porto Alegre, n. 26, p. 204-222, jul. 2012.

BATISTA, C. L. Mediação e apropriação: questões do direito de acesso à informação. In: MOURA, Maria Aparecida (Org.). A construção social do acesso público à informação no Brasil: contexto, historicidade e repercussões. Belo Horizonte: UFMG, 2014. p.137-152.

BERNARDES, M. B.; SANTOS, P. M.; ROVER, A. J. Ranking das prefeituras da região Sul do Brasil: uma avaliação a partir de critérios estabelecidos na Lei de Acesso à Informação. Revista de Administração Pública, Rio de Janeiro, v. 49, n. 3, p. 761-792, maio/jun., 2015.

BEHLKE, F. P. C. Cultura organizacional no serviço público: análise histórica. Caderno Gestão Pública, v. 4, n. 3, p. 44-52, jul./dez. 2014. Disponível em: $<$ http://www.grupouninter.com.br/revistaorganizacaosistemica/index.php/cadernogestaopubl ica/article/view/301> Acesso em: 25 jul. 2014. 
BRAGA, M. V. A. A auditoria governamental como instrumento de promoção da transparência. In: CONGRESSO CONSAD DE GESTÃO PÚBLICA, 4., 2011, Brasília, 2011. Disponível em: $<$ https://bvc.cgu.gov.br/bitstream/123456789/3676/4/auditoria governamental como instru mento transpar\%C3\%AAncia.pdf>Acesso em: 02 dez. 2017.

BRASIL. CONTROLADORIA GERAL DA UNIÃO. Acesso à informação pública: uma introdução à Lei 12.527, de 18 de novembro de 2011. Brasília: CGU, 2011.

BRASIL. CONTROLADORIA GERAL DA UNIÃO. Política Brasileira de Acesso a informações Públicas: garantia democrática do direito à informação, transparência e participação cidadã. Brasilia: CGU; UNESCO, 2010.2 Disponível em: <http://www.acessoainformacao.gov.br/acessoainformacaogov/acessoinformacaorasil/projeto-cgu-unesco/Projeto-de-Cooperacao-Tecnica-entre-o-GovernoBrasileiro-e-a-UNESCO.pdf>

Acesso em: 29 set. 2017.

BRASIL. CONTROLADORIA GERAL DA UNIÃO. Panorama geral da implementação da LAI. Brasília: CGU, 2014. Disponível em: <www.acessoainformacao.gov.br/lai'para'sic/sic-apoioorientacoes/redes-sics/arquivos/palestra1-sergioseabra.pdf> Acesso em: 01 fev. 2018.

BRASIL. CONTROLADORIA GERAL DA UNIÃO. Relatório sobre a implementação da Lei no 12.527: Lei de Acesso à Informação. Brasília: Ministério da Transparência, Fiscalização e Controladoria-Geral da União, $2016 . \quad$ Disponível em: $<$ http://www.acessoainformacao.gov.br/central-deconteudo/publicacoes/relatorio 4anos web.pdf2015> Acesso em: 10 jan. 2018

BRASIL. CONTROLADORIA GERAL DA UNIÃO. Relatório sobre a implementação da Lei no 12.527: Lei de Acesso à Informação. Brasília: Ministério da Transparência, Fiscalização e Controladoria-Geral da União, 2017. Disponível em: $<$ http://www.acessoainformacao.gov.br/central-deconteudo/publicacoes/relatorio 4anos web.pdf2015> Acesso em: 13 jan. 2018.

BRUNI, A. SPSS guia prático para pesquisadores. São Paulo: Atlas, 2012.

CARAPETO, C; FONSECA, F. Antecipação e gestão da mudança. In: CARAPETO, C; FONSECA, F. Administração Pública. Lisboa: Silabo, 2014. Cap. 7.

CARVALHO, P. F. de. Os efeitos da lei de acesso à informação na gestão das informações arquivísticas: caso da Universidade Federal do Rio de Janeiro. 2014. 182 f. Dissertação (Mestrado em Ciência da Informação)- Universidade Federal Fluminense, Rio de Janeiro, 2014.

CUNHA, M. B. da.; CAVALCANTI, C. R. O. Dicionário de Biblioteconomia e Arquivologia. Brasília: Briquet de Lemos, 2008.

CRUZ, E. B. Acesso e gestão da Informação governamental do tipo arquivístico: aspectos técnicos e a visão de gestores e servidores de duas instituições governamentais. 2016. $226 \mathrm{f}$. Tese (Doutorado em Ciência da Informação) - Instituto Brasileiro de Informação, Ciência e Tecnologia, Universidade Federal do Rio de Janeiro, Rio de Janeiro, 2016.

DA MATTA, R. (coord.). Pesquisa diagnóstico sobre valores, conhecimento e cultura de acesso à informação pública no Poder Executivo Federal Brasileiro. Brasília: CGU, 2011. 
FACHIN, J. Acesso à informação pública nos arquivos públicos estaduais. 2014. $164 \mathrm{f}$. Dissertação (Mestrado em Ciência da Informação) - Universidade Federal de Santa Catarina, Florianópolis, 2014.

FERREIRA, E. G. A.; SANTOS, E. S; MACHADO, M. N. Política de informação no Brasil: a lei de acesso à informação em foco. Múltiplos olhares em Ciência da Informação, v. 2, n. 1, mar. 2012.

FROTA, M. G. C. Comissão Nacional da Verdade e Lei de Acesso à Informação: informação, memória e justiça no contexto democrático pós-1988. In: MOURA, Maria Aparecida (Org.). A construção social do acesso público à informação no Brasil: contexto, historicidade $e$ repercussões. Belo Horizonte: UFMG, 2014. p. 71-84.

FOX, J.; HAIGHT, L.; PALMER-RUBIN, B. ¿Proporcionar transparencia? Hasta qué punto responde el gobierno mexicano a las solicitudes de información pública. Gestión y Política Pública, Ciudad de México, v. 20, n. 1, Jan. /jun. 2011.

GAMA, J. R. Instrumentos de transparência e acesso às informações públicas: um estudo das demandas por informações contábeis nas universidades federais. 2015. 189 f. Tese (Doutorado em Ciência da Informação) - Universidade de Brasília, Brasília, 2015.

GIL, A. C. Métodos e técnicas de pesquisa social. São Paulo: Atlas, 2014.

GIMÉNEZ CHORNET, Vicent et al. Gobierno abierto en la Comunidad Valenciana. Métodos de Información, Valencia, v. 4, n. 7, p. 129-153, 2013.

HAIR JR, Joseph F. et al. Análise multivariada de dados. 6. ed. Porto Alegre: Bookman, 2009.

INDOLFO, A. C. O acesso às informações públicas: retrocessos e avanços da legislação brasileira. Informação Arquivística, Rio de Janeiro, v .2, n. 1, p. 4-23, jan./jun., 2013.

LIMA, M. H. T. de F.; CORDEIRO, H. C. D.; GOMES, C. A. de S. Antecedentes e perspectivas do direito à informação no Brasil: a Lei de Acesso à Informação como marco divisor. In: MOURA, M. A. (Org.). A construção social do acesso público à informação no Brasil: contexto, historicidade e repercussões. Belo Horizonte: UFMG, 2014. p. 47-69.

LYRIO, M. V. L. Transparência da gestão pública em portais eletrônicos: uma análise no contexto do poder executivo dos governos subnacionais brasileiro e espanhol. 2016. 295 f. Tese (Doutorado em Administração) - Universidade Federal de Santa Catarina, Florianópolis, 2016.

MALHOtRA, N. K. Pesquisa de marketing: uma orientação aplicada. 6. ed. Porto Alegre: Bookman, 2012.

MARTINS, A. A. L.; REIS, A. S. A informação pública como direito e acesso ao poder: a Lei 12.527/2011 em debate. In: MOURA, M. A (Org.). A construção social do acesso público à informação no Brasil: contexto, historicidade e repercussões. Belo Horizonte: UFMG, 2014. p.153-172.

MEDEIROS, S; MAGALHÃES, R; PEREIRA, J. R. Lei de Acesso à informação: em busca da transparência e do combate à corrupção. Informação e Informação, Londrina, v. 19, n. 1, p. 5575, jan./abr. 2014. 
MENDEL, T. Liberdade de informação: um estudo de direito comparado. 2. ed. Brasília: Unesco, $2009 . \quad$ Disponível em: $<$ http://portal.unesco.org/ci/en/files/26159/12639855119freedom information pt.pdf $>$ Acesso em: 30 jul. 2015.

MIRANDA, V. L. Aspectos arquivísticos da aplicação da Lei de Acesso à informação nas universidades federais do Estado do Rio de Janeiro (maio de 2012 a maio de 2014). 2015. 125 f. Produto técnico-científico (Mestrado profissional em Gestão de Documentos e Arquivos)Universidade Federal do Estado do Rio de Janeiro, Rio de Janeiro, 2015.

MOURA, M. A. Introdução. In: MOURA, M. A. (Org.). A construção social do acesso público d̀ informação no Brasil: contexto, historicidade e repercussões. Belo Horizonte: UFMG, 2014. p.19-23.

OLIVEIRA, R. S. de; RAMINELLI, F. P. O direito ao acesso à informação na construção da democracia participativa: uma análise da página do Conselho Nacional de Justiça no Facebook. Sequência, Florianópolis, n. 69, p. 159-182, dez. 2014.

ORGANIZAÇÃO DAS NAÇÕES UNIDAS. Declaração Universal dos Direitos do Homem. 1948. Disponível em $\quad<$ http://www.gddc.pt/direitos-humanos/textos-internacionaisdh/tidhuniversais/cidh-dudh.html> Acesso em: 29 dez. 2017.

ORGANIZAÇÃO DAS NAÇÕES UNIDAS. Transformando nosso mundo: a agenda 2030 para o desenvolvimento sustentável. [Brasília]: ONU, 2017. Disponível em: <https:nacoesunidas.org/pos2015/agenda2030/> Acesso em: 23 jan. 2018.

RAMOS VOLONTERIO, M. de L; VILLAR, A. El acceso a la información pública y los archivos em Uruguay. Palabra Clave, La Plata, v. 3, n. 1, p. 45-51, mayo/out. 2013.

RUIJER, E. H. J.M. Proactive transparency in the United States and the Netherlands: the role of Government Communication Officials. American Review of Public Administration, New York, v. 47, n. 3, p. 354-375, 2017.

SAMARA, B. S.; BARROS, J. C. Pesquisa de marketing: conceitos e metodologia. 4. ed. São Paulo: Pearson Prentice Hall, 2007.

SANDOVAL BALLESTEROS, I. E. Hacia un proyecto "democrático-expansivo" de transparencia. Revista Mexicana de Ciencias Políticas y Sociales, Ciudad del México, v. 58, n. 219, 2013.

SOUZA, F. J. V. de et al. Lei de Acesso à informação: um estudo na Universidade Federal do Rio Grande do Norte. Ciências Sociais em perspectivas, Cascavel, PR, v. 14, n. 26, p. 101-119, 2015.

TERRA, L. B. A implementação da Lei de Acesso à Informação (LAI) na Universidade Federal da Bahia. 2014. 103 f. Dissertação (Mestrado em Administração)- Universidade Federal da Bahia, Salvador, 2014.

TRISTÃO, G. Transparência na administração pública. In: CONGRESO INTERNACIONAL DEL CLAD SOBRE LA REFORMA DEL ESTADO Y DE LA ADMINISTRACIÓN PÚBLICA, 7., 2002, Lisboa. Disponível em: $<$ http://unpan1.un.org/intradoc/groups/public/documents/clad/clad0043714.pdf > Acesso em: 02 jul. 2015. 
UHLIR, P. F. Diretrizes políticas para o desenvolvimento e a promoção da informação governamental de domínio público. Brasília: UNESCO, 2006.

UVALLE BERRONES, R. Fundamentos de la transparência em la sociedade contemporânea. Revista Mexicana de Ciencias Políticas y Sociales, Ciudad de México, v. 61, n. 226, jan. /abr. 2016.

VIEIRA, V. L. R. Efeitos da Lei de acesso à informação (Lei 12.527/2011) nas compras públicas. In: CONGRESSO CONSAD DE GESTÃO PÚBLICA, 6, 2013, Brasília. Anais eletrônicos... Brasília: 2013.

WARRICK, D. D. What leaders need to know about organizational culture. Business Horizons, v. 60, p. 395-404, 2017.

ZORZAL, L. Transparência das informações das universidades federais: estudo dos relatórios de gestão à luz dos princípios de boa governança na Administração Pública Federal. 2015. 197 f. Tese (Doutorado em Ciência da Informação) - Universidade de Brasília, Brasília, 2015. 